appropriate emphasis given the quality of the available evidence base. There has to be some delay in publication (perhaps not surprisingly, given the size and complexity of the volume) and the most recent references are to the year 2001. The field is expanding so rapidly that I urge the editors to start a new edition, constantly updating in a manner akin to painting the Forth Bridge.

Nicol Ferrier Professor of Psychiatry, University of Newcastle, School of Neurology, Neurobiology and Psychiatry, Royal Victoria Infirmary, Queen Victoria Road, Newcastle upon Tyne NEI 4LP, UK

\section{Substance Misuse in Psychosis. Approaches to Treatment and Service Delivery}

Edited by Hermine L. Graham, Alex Copello, Max J. Birchwood \& KimT. Mueser.

Chichester: Wiley. 2003. 420 pp. $€ 65.00$ (hb). ISBN 0 47I 492299

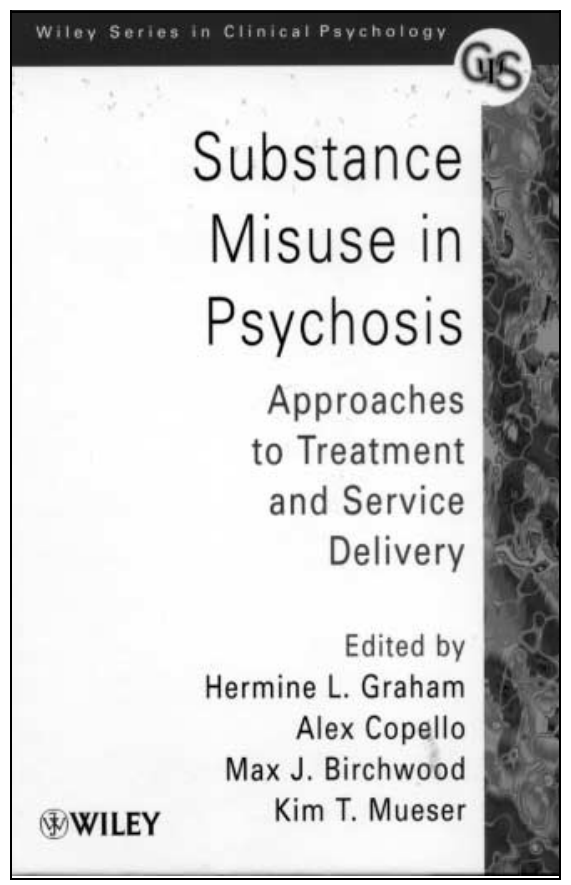

The high prevalence of alcohol and drug misuse in those with psychiatric illness is apparent to all who work within adult psychiatry. Traditionally, mental health and addiction services have operated in parallel. Differences between the two services in terms of organisation, geographical location and philosophy of care have often meant that patients have fallen between the two, leading to frustration for patients, families and staff. The past 10 years have seen increased understanding of the reasons for this comorbidity, the development of innovative integrated treatment services and the introduction of new treatments for substance misuse. This book provides a comprehensive review of these developments.

The book is divided into five parts. The first serves as an introduction, and begins with two chapters on the epidemiology of substance misuse in psychosis and the temporal relationship between the two. This is followed by three excellent chapters looking at family, social and cognitive conceptualisations, the first of which highlights the relationship between substance misuse in psychosis and the patient's family and social networks, including the role of expressed emotion. The sociological perspective that follows makes some interesting points in relation to stigma and the negative attitudes held not only by the public but also by clinicians managing this group of patients. In the first part's final chapter, Hermine L. Graham emphasises the importance of a cognitive formulation in managing patients, and how it can be used to generate hypotheses that can be tested and act as a guide for treatment interventions.

Part 2 reviews integrated service models, including community-based and inpatient treatment programmes. Examples are provided from the USA and the UK, including the Combined Psychosis and Substance Use (COMPASS) programme in north Birmingham. Part 3 considers assessment and treatment approaches such as cognitive-behavioural therapy, group therapy and family interventions. There is a single chapter on pharmacological approaches, which, although well written, is too short, with the result that many key areas are skimmed over. The editors should consider expanding this chapter in a future edition. Part 4 considers the needs of special populations, including the homeless and those with HIV/AIDS. Part 5 examines treatment outcome studies and looks towards future developments.

Over forty authors, mainly from the USA and the UK, have contributed. The editors have ensured that throughout the material remains clinically relevant, and many chapters employ illustrative case reports to good effect. This is a wellplanned and well-written book, and I recommend it.

Peter Haddad Consultant Psychiatrist, Cromwell House, Bolton, Salford and Trafford Mental Health Partnership, Eccles M30 OGT, UK

\section{Child Psychiatry and Psychology: An Introduction}

Edited by David H. Skuse. Abingdon: Medicine Publishing Company. 2003.

228 pp. $€ 29.00$ (pb). ISBN 0953259854

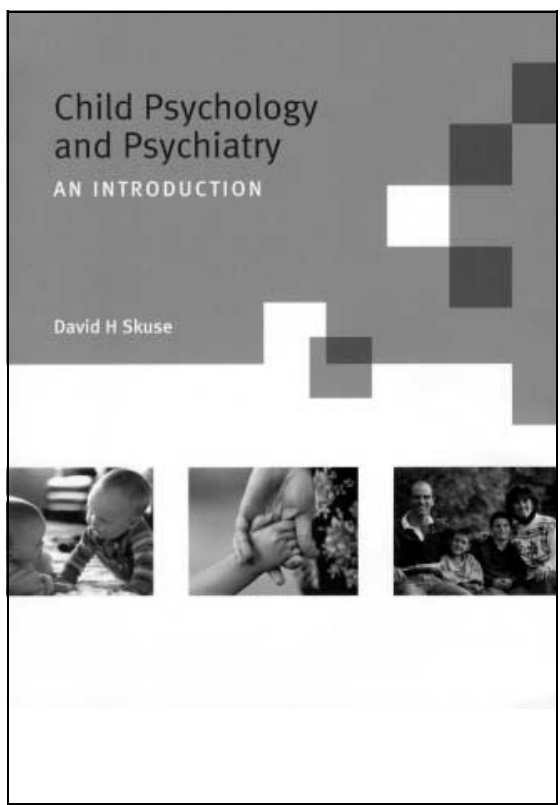

This book integrates developmental child psychology and an introduction to child psychiatry in a modestly sized guide to clinical practice by packing information into succinct chapters and excellent summarising tables. It spans normal development, assessment, family and genetic influences, classification, developmental and psychiatric disorders, management and treatment issues, and child psychiatry and the law. The authoritative contributors produce chapters that are easy to digest.

The assessment section offers excellent chapters on the assessment of psychiatric disorders in children, developmental paediatric and specialist neuropsychological assessment, IQ testing and scales to measure behavioural and emotional adjustment in children and their families. Summaries of other models that often contribute to a psychiatric assessment 